\title{
Digital three-dimensional architectural survey of traditional Bulgarian houses - architectural BIM from point cloud survey data
}

KLIMENT IVANOV

Department of Architecture, New Bulgarian University, Sofia, Bulgaria.

klivanov@nbu.bg

\section{Levantamento arquitectónico digital tridimensional de casas tradicionais búlgaras - BIM arquitectónico a partir de dados de levantamentos em nuvem de pontos}

\begin{abstract}
Nowadays the technology is often ahead of its implementation in the practice. Two novel technologies have affected the field of conservation and documentation of cultural and historic heritage and await their proper mutual integration. They are the 3D photogrammetric surveying and the Building Information Modelling (BIM). This research proposes a methodology for producing a complete and precise 3D Building Information Model from a point cloud, obtained via a 3D photogrammetric survey. An existing traditional house in Bulgaria is used as a case study. The aims were to optimise the process and to minimise the large number of software, used in the conventional workflow. They were achieved using only one application - ArchiCAD version 22. The complete BIM was later used for producing $3 \mathrm{D}$ artistic visualisations and for an interactive $3 \mathrm{D}$ web presentation. This paper describes the methodology and the software needed, discussing the techniques and the results.
\end{abstract}

\section{Resumo}

Actualmente, a tecnologia está frequentemente à frente da sua implementação prática. Duas novas tecnologias afectaram o campo da conservação e documentação do património cultural e histórico e aguardam a sua adequada integração mútua: o levantamento fotogramétrico em 3D e a modelação da informação na construção (BIM). Esta pesquisa propõe uma metodologia para a produção de um Modelo de Informação de Construção 3D completo e preciso a partir de uma nuvem de pontos, obtida por meio de um levantamento fotogramétrico em $3 \mathrm{D}$. Uma casa tradicional existente na Bulgária é usada como estudo de caso. Os objectivos eram optimizar o processo e minimizar o grande número de softwares utilizados no fluxo de trabalho convencional. Eles foram alcançados usando apenas um aplicativo - ArchiCAD versão 22.0 BIM completo foi posteriormente utilizado para produzir visualizações artísticas em 3D e para uma apresentação 3D interactiva na web. Este artigo descreve a metodologia e o software necessários, discutindo as técnicas e os resultados.

\section{KEYWORDS}

BIM

ArchiCAD

Cultural Heritage Traditional Houses Reconstruction Virtual Presentation

\section{PALAVRAS-CHAVE}

BIM

ArchicAD

Património Cultural

Casas tradicionais

Reconstrução

Apresentação virtual 


\section{Introduction}

In recent years, Building Information Modelling (BIM) has been the indisputable leader among the platforms for integrated architectural design. It has established as an invaluable tool in the field of documentation and preservation of cultural heritage too [1]. Moreover, a concept to integrate the model with survey data and extra information about the lifecycle of the building has been proposed and put into practice as "Historical BIM (HBIM)" [2].

Many historically valuable traditional houses in Bulgaria are in poor condition and there is a pending "real danger that many of these monuments will be destroyed irretrievably and lost for the future generations" [3]. A major step in preserving this national treasure is to make a thorough survey of as many as possible of these buildings before their actual destruction or loss and create a comprehensive digital archive. It will provide a basis for restoration and adaptation of these buildings to the modern conditions in the future.

Nowadays there are tools and capabilities to obtain various forms of data about a historical building and store massive amounts of it. This is gaining importance with the invention of the $3 \mathrm{D}$ laser scanning and photogrammetric survey technologies. This data is valuable for documentation and preservation purposes. But, when it comes to the actual implementation of it in architectural design for restoration, reconstruction, and adaptation of the historic buildings, the architects are baffled with the problem how to access and use it in practice. In reality there is "a total lack of accessibility to the entire corpus of information that should be shared by the specialists" and it is broken into "discontinuous isolated parts" [4]. The problem is that this data comes in the form of "unstructured datasets [...] that need to be converted to structured 3D models for useful further applications" [5]. The fluent transformation of the survey data into a building information model, suitable for architectural design, is still a process that creates serious obstacles and is in need of improvement.

Contemporary 3D modelling and Computer Aided Architectural Design (CAAD) software is able to open and use as a reference extra-large point clouds, generated from 3D survey data. The point cloud data can be generated from laser scanning or photogrammetric survey. But opening of large triangulated surface meshes in 3D CAAD applications is still impossible [6].

The aim of this research is to propose a practical and tested workflow for producing a precise and usable BIM from 3D point cloud survey data. The BIM is intended to facilitate both architectural design and cultural heritage restoration and reconstruction. For the purpose of this article, it may be called "Architectural BIM" in order to differentiate it from the BIM in general. The goal is to produce a refined working building information model within the shortest possible time frame and with the use of minimal number of software applications.

The proposed workflow benefits from the author's almost twenty-year experience as a practising architect and a university lecturer in computer-aided architectural design and $3 \mathrm{D}$ modelling.

\section{The house}

A prominent historic house in the city of Shumen in Bulgaria had been chosen for the case study (Figure I). It is known as the Srebrov House (in Bulgarian: Среброва къща) and is a designated cultural property, part of the national cultural heritage. It is an example of traditional Bulgarian architecture from the end of the nineteenth century.

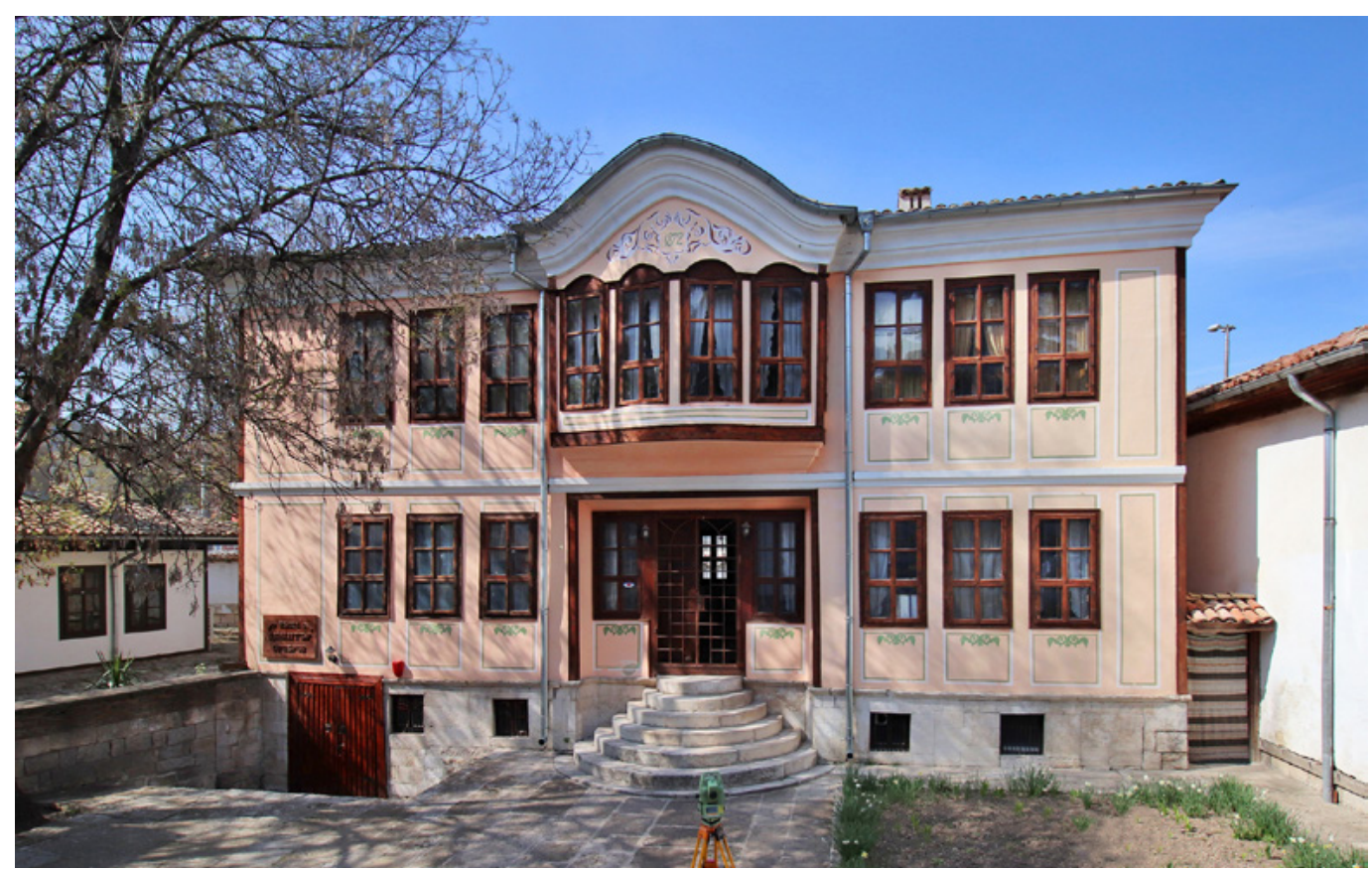

Figure 1. Srebrov House, photo with the main entrance, Georgi Georgiev. 
The house has been selected because of its geometry, which is characteristic of many traditional houses. It consists of simple volumes and elements plus several complex forms. The simple ones are: planes for the walls, boxes and cylinders for the stairs and others, various intersected pyramidal forms for the roofs, extruded complex shapes for the cornices, windows and doors, and railings. The complex ones are: the cantilevered part on the second storey, formed by two intersecting space shapes, and the complex profile of the cornice, following a space curve.

In its capacity as a cultural property, the house had been a subject of previous surveys via traditional methods. Detailed architectural drawings of it had been published in the seminal book on the architecture of the city Shumen Revival Houses (translation by the author, in Bulgarian: Шуменски възрожденски къщи) by Rashel Angelova [7]. A more recent $2 \mathrm{D}$ digital architectural survey, based on geodetic data, was also obtained, with the cooperation of the local municipality. These surveys provide valuable extra information for comparison with the photogrammetric survey and the BIM model.

The team of surveyors supplied a point cloud, obtained via a $3 \mathrm{D}$ photogrammetric survey, which was used as a basis for the BIM.

\section{The point cloud}

The photogrammetric survey consists of two separate stages - a photographic survey and a geodesy survey. The photographic survey is made with a digital single-lens reflex camera (DSLR) in three sessions - from the ground, mounted on a drone for aerial photos, and mounted on a drone for photos parallel to the elevation planes. The camera is Canon EOS 77D. The drones are DJI Mavic Pro and DJI Phantom 4 Pro. The data is verified with a geodesy survey, made with a Global Navigation Satellite System (GNSS) Leica ATX 1200 and a Leica TCRA1100+ total station. Three pointclouds are generated from the sessions and are merged into a single one, geodetically linked to a coordinate system [8]. An orthophoto and a triangulated 3D Digital Surface Model (DSM) have also been generated, but the later was not used because of its extremely large polycount [6].

\section{The software}

The selected BIM software is Graphisoft ArchiCAD, developed by the Nemetschek group. The latest available version is used with an educational licence - 22 EDU. The reason for its choice is that an intuitive and reliable application, which could secure a stable workflow, was needed. ArchiCAD complies with these requirements. It is one of the first real BIM applications [9]. The concept of HBIM also relies on ArchiCAD with the development of specialized libraries [5]. An elaborate comparison between "the two leading parametric modelling software", ArchiCAD and Autodesk Revit, had been carried out for "producing a detailed BIM of built heritage with complex shapes" [10] and ArchiCAD outmatched its competition by several criteria.

\section{Modelling}

\section{Trimming the point cloud in ArchiCAD}

The point cloud can be opened in ArchiCAD as a Library Part, kept in an external library folder. In this way, it does not increase the file size and makes working with the file easier - "The fact that the point cloud was not kept inside the .pln file allowed for a very fast and trouble-free work within the application" [6]. The point cloud, obtained from the 3D photogrammetric survey, covers the area of the house with the courtyard, the street, and the nearby trees (Figure $2 a$ ). A large part of this information is not needed for the modelling of the house and is better to be removed for easier handling of the point cloud. This poses a problem because most CAAD and $3 \mathrm{D}$ modelling applications cannot manipulate point clouds and thus an additional application is required. An important advantage of ArchiCAD is its ability to trim the point cloud without the need of third-party software. This is done with the $3 D$ Cutaway function using custom $3 D$ Cutting Planes (Figure $2 b$ ). The trimmed parts are not deleted but are excluded from the 3D calculation and visualisation. They can always be brought back with a single shortcut.
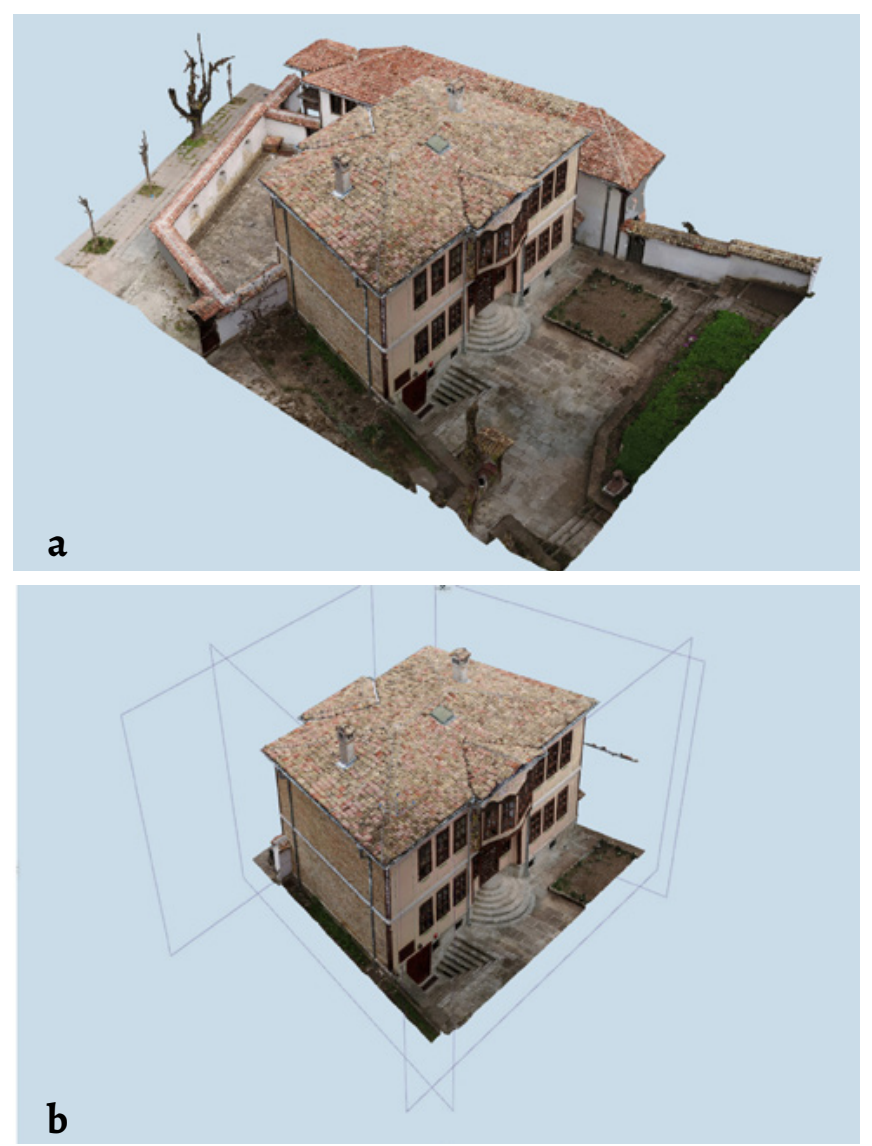

Figure 2. The point cloud in ArchiCAD: $a$ ) in full; $b$ ) trimmed. 


\section{Modelling of the main volumes - Section generation modelling method}

The popular method for modelling from 3D laser scanned or photogrammetric data is by extracting contours via horizontal and vertical sections from a triangulated mesh. For this purpose the initial point cloud has to be triangulated beforehand, to produce a surface that could be cut. Usually, cutting is done in third-party 3D modelling software like Rhino or 3dsMax. In the past (2009), the resulting rough contour had to be brought to a CAAD application for cleaning and redrawing, and only after that used for modelling in the $3 \mathrm{D}$ application [11]. Nowadays the contour cleaning and the modelling can be done in the BIM application itself [10, 12-13].

ArchiCAD provides the opportunity to cut the point cloud directly and obtain a traceable contour. The contour can be redrawn (as a group of lines and curves, a polyline, or a fill) and used for modelling of the BIM. All of these operations can be done in ArchiCAD without the need of additional software. The horizontal sections are made with the Storeys function directly in the floor plan (Figure $3 a$ ). The vertical position of the sections is controlled by adjusting the Floor Plan Cut Plane and each position can be saved separately. The vertical sections are made with the Section Tool, characteristic for the application since its creation. By adjusting the Horizontal Range of the section, a very thin contour can be obtained (Figure 3b).
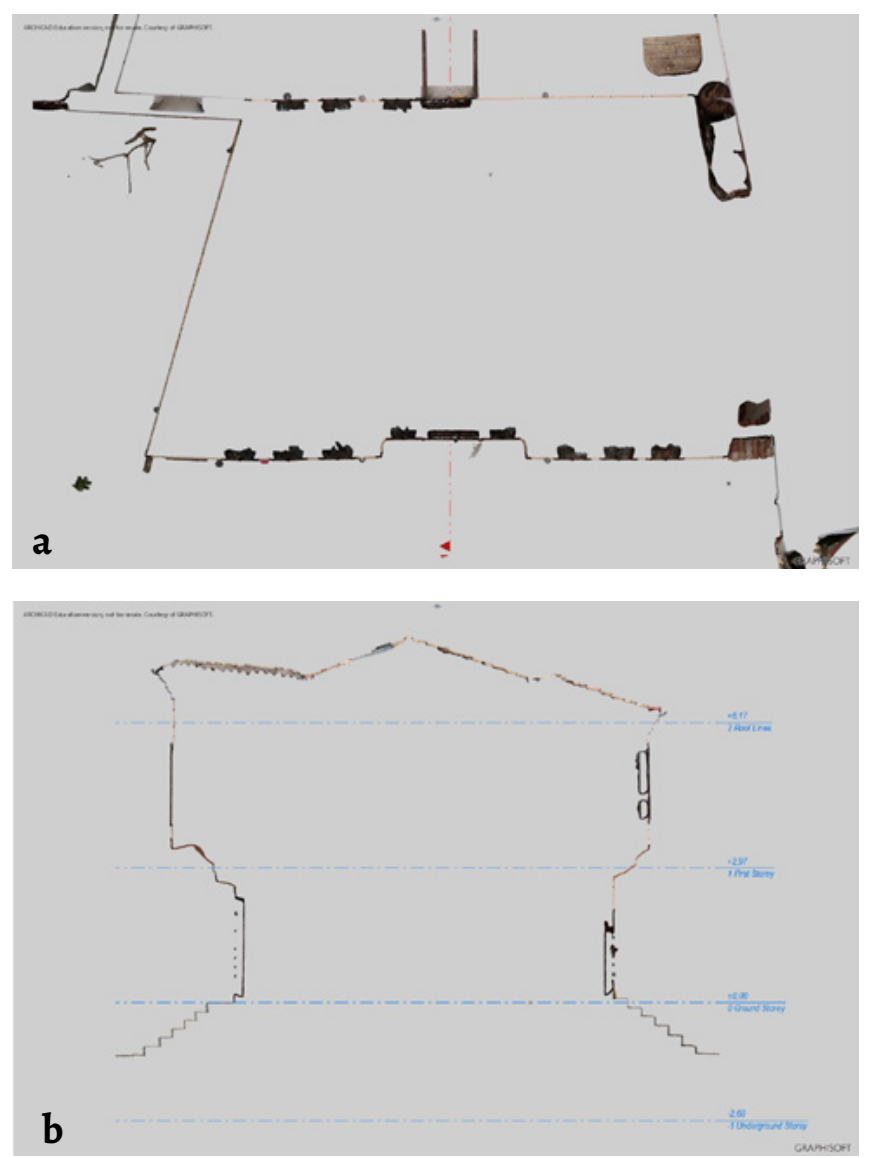

Figure 3. Sections through the point cloud in ArchiCAD: a) horizontal at height $1,20 \mathrm{~m}$; $b$ ) vertical 1-1, depth $10 \mathrm{~cm}$.

\section{Modelling of the main volumes $-3 \mathrm{D}$ volumes modelling method}

In this case study, a different method for $3 \mathrm{D}$ modelling is implemented, thanks to the enhanced capabilities of ArchiCAD. It can be called the " $3 \mathrm{D}$ volumes modelling method". The volumes are modelled directly with threedimensional elements that are superimposed over the point cloud. The process is carried out simultaneously in the Floor Plan, the Sections and the $3 \mathrm{D}$ windows, depending on which view is more convent (Figure 4a). The modelling is done with native ArchiCAD 3D elements, both for planar and curved surfaces. These elements are called Tools and they include Walls, Columns, Slabs, Roofs, Shells, Morphs and Meshes. They are manipulated until the best overlapping with the point cloud is achieved by moving, rotating, tilting, stretching, pushing, etc. Painting the new elements with a contrasting colour enhances the visibility and hence the control over the process. In cases when the use of Objects (GDL Library Parts) is required, still native library parts from the standard library are preferred, instead of creating scripted or modelled customised ones (Figure 4b). The native elements in ArchiCAD have built-in Classification and Properties options Elements IDs, IFC IDs, Layers, etc. They allow a very high level of identification and documentation to be achieved.
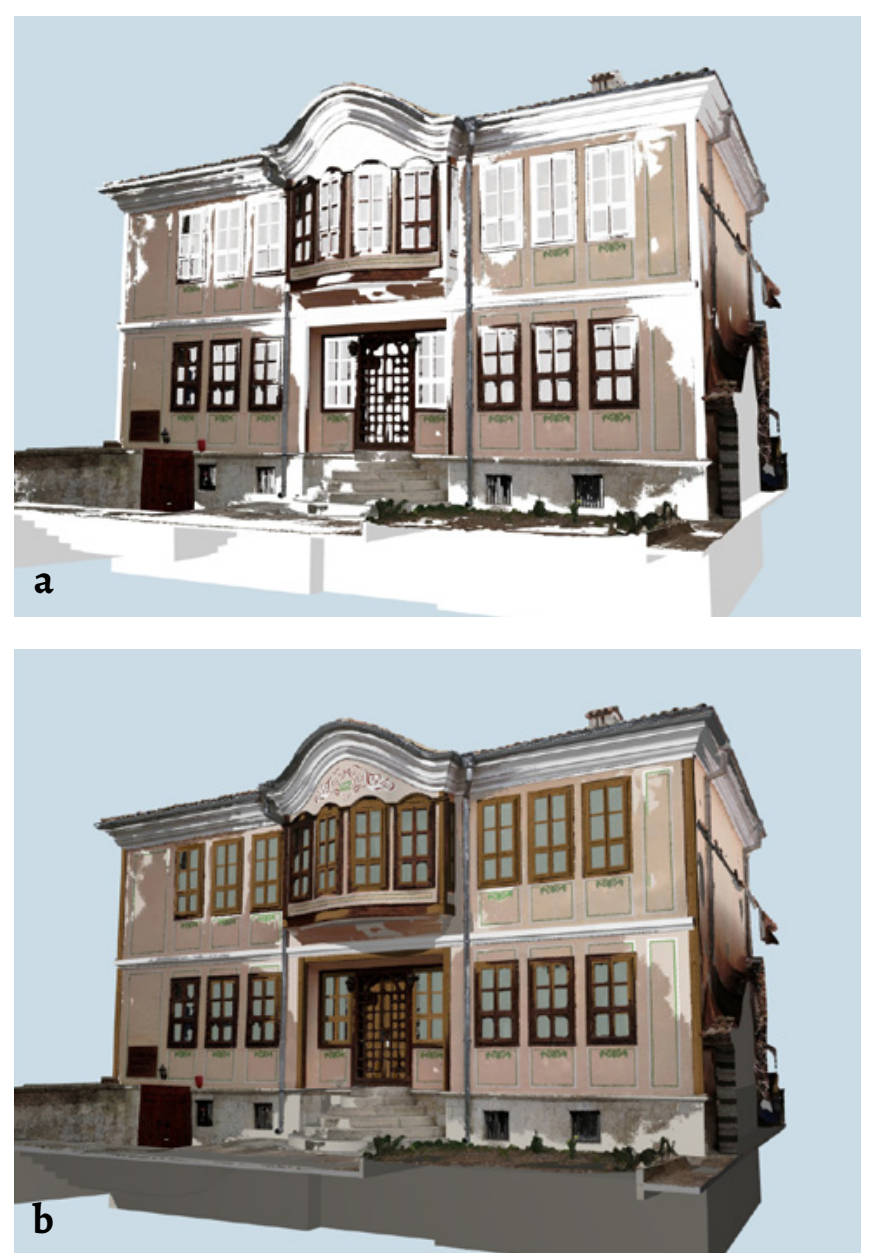

Figure 4. 3D volumes superimposed over the point cloud: a) white colour; b) contrasting solid colour. 
A similar approach was chosen by other researchers, who used 3D elements that "were positioned so that the deviation standard between $\mathrm{x}, \mathrm{y}, \mathrm{z}$ coordinates of the point cloud and the surface of the elements was minimum" [14], but they overlapped the point cloud with Library Objects instead of the native $3 \mathrm{D}$ elements. This approach is based on the earlier Historic BIM (HBIM) concept, which relies on the development of customised parametric libraries with ArchiCAD's native scripting language GDL (Geometric Description Language) [2, 5].

The $3 \mathrm{D}$ volumes modelling method increases the accuracy of the new geometry and greatly reduces the time needed for creating the model. It proves to be more precise than the previous one. It does not rely only on "the number of section planes" [13] to define the form, but superimposes the form upon the point cloud. Thus, the interaction between the point cloud and the $3 \mathrm{D}$ volume is directly visualized. The method also avoids the need for scripting, which is time-consuming and can be done only by highly skilled professionals. Besides, the architects are more natural in modelling than coding. It is also significantly more fluent as the conversions and transfers between several separate applications are avoided.

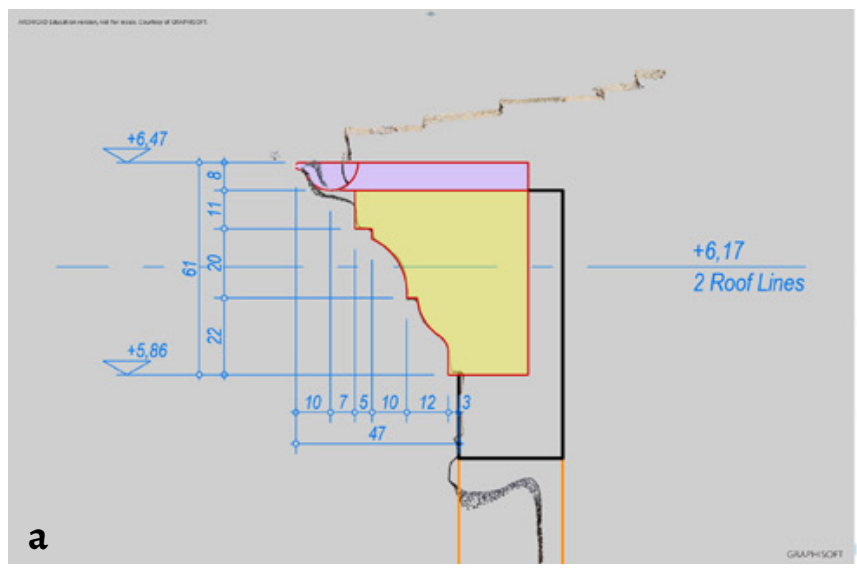

\section{Modelling of specific elements}

Linear elements consist of a profile, extruded along a path. They include cornices, mouldings, pilasters, railings, etc. The contour of the profile is obtained via a partial section through the point cloud and is redrawn (Figure $5 a$ ). With the Custom Profile function, it is extruded along a path (straight or curved) using the Wall, Beam or Column Tools, generating a native ArchiCAD 3D element. In this case, the Beam Tool is preferred because it can automatically interact with the Wall element and subtract its volume from it. The new volume is superimposed upon the point cloud and its form can be checked against the existing geometry. The function is fully parametric and, when the initial contour is changed, the transformations are immediately reflected in the $3 \mathrm{D}$ geometry (Figure 5b).

Curved surfaces are modelled via a combination of techniques. The cantilevered volume above the main entrance follows a triple-arc curve, characteristic for the traditional Bulgarian architecture, called kobillitza (in Bulgarian: кобилииа). It is modelled with a Wall, following the curve in plan, and is cut by an extruded surface, following a similar curve in elevation. As a result, a space curve is extracted and is used as a path for extrusion of the profile of the cornice on top (Figure 6a).

Figure 5. Section through the roof cornice with the redrawn contour (a). 3D view of the Custom Profile (b).
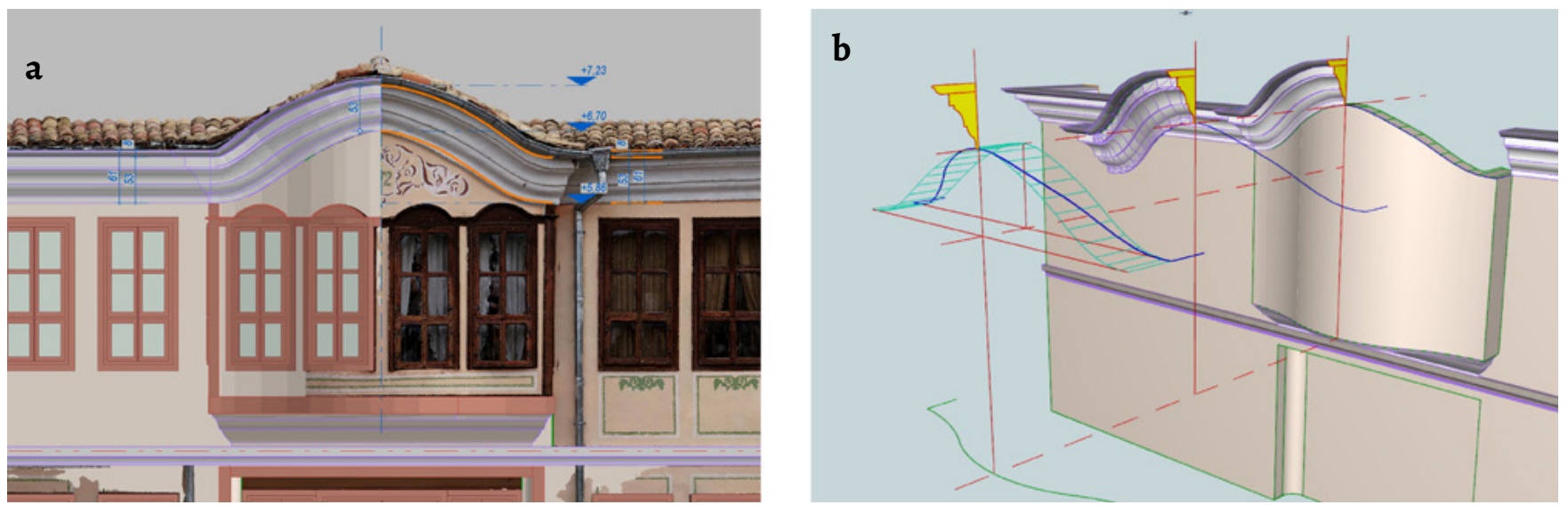

Figure 6. The triple-arc curve in elevation view, traced with a spline (a). Modelling the cornice, based on a space curve (b). 
The restriction of the above mentioned Custom Profile function is that the path has to lie in a single plane, i.e., it has to be a flat curve. The extrusion along the space curve is done manually, using the Morph Tool. It results in a complex segmented form that is not fully parametric. Selective smoothing of the segments is needed to keep the vertical edges sharp and the horizontal ones smooth. This operation has to be done manually too (Figure $6 b$ ). The windows and doors of the house are historic building elements that are very different from today's ones. They are modelled entirely with the native ArchiCAD Window Tool and Doors Tool and are fully parametric. These tools offer an extensive set of parameters for modelling even the most demanding custom elements (Figure 7a).

All the painted decoration is three-dimensionally modelled. It is modelled with surfaces, parallel to the main volumes, intersected with Custom Profiles, which define the pattern. In this way, the patterns can be considered as parametric, because once put in place, they all can be changed by changing the contour of the Custom Profile. If needed, the geometry can be further refined or complicated (Figure $7 b$ ). Usually, such decoration is applied as bitmaps during the rendering stage. Modelling it provides more control over the geometry of the pattern and keeps the consistency of the BIM.

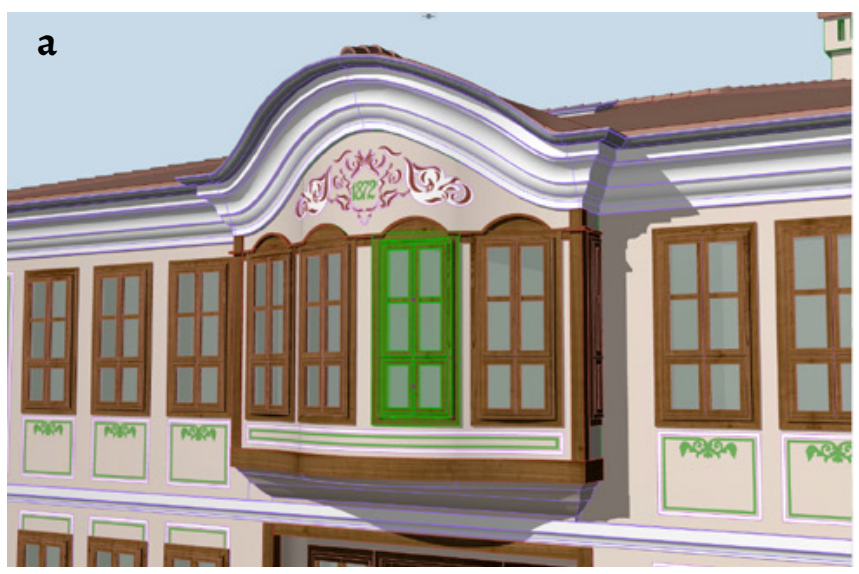

\section{Visualisation}

The visualisations are made using the original model from ArchiCAD without any further modifications (Figure $8 a$ and Figure 8b). The platform is Autodesk 3dsMax. New materials from the modelling application are applied. The rendering is done with Chaos Group V-Ray Edu 3.60.04 engine (Figure $9 a$ and Figure 10). Post-production and photomontages are done in Adobe Photoshop CS6.

An interactive $3 \mathrm{D}$ model is produced and published online (Figure $9 b$ ). It provides an avant-garde way of showcasing and accessibility. It can be viewed, zoomed and rotated directly in the web browsers without the need for other specialized software. The interactive $3 \mathrm{D}$ model is generated with the Sketchfab 3dsMax Exporter plug-in. It is published on the web site of the New Bulgarian University.

\section{Discussion}

\section{Obstacle}

The major obstacle in the modelling was that the decimated mesh could not be imported into the CAAD applications because of its size of more than 1 million polygons. As it has been shown in the author's previous research, meshes with extra-large polycount still cannot be opened and processed

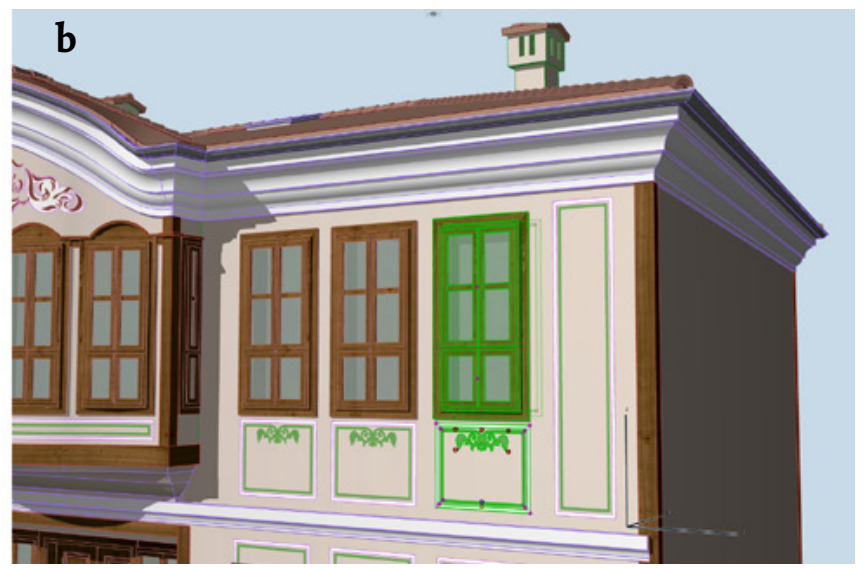

Figure 7. Windows detail (a). Decoration pattern detail and decoration only in 3D (b).
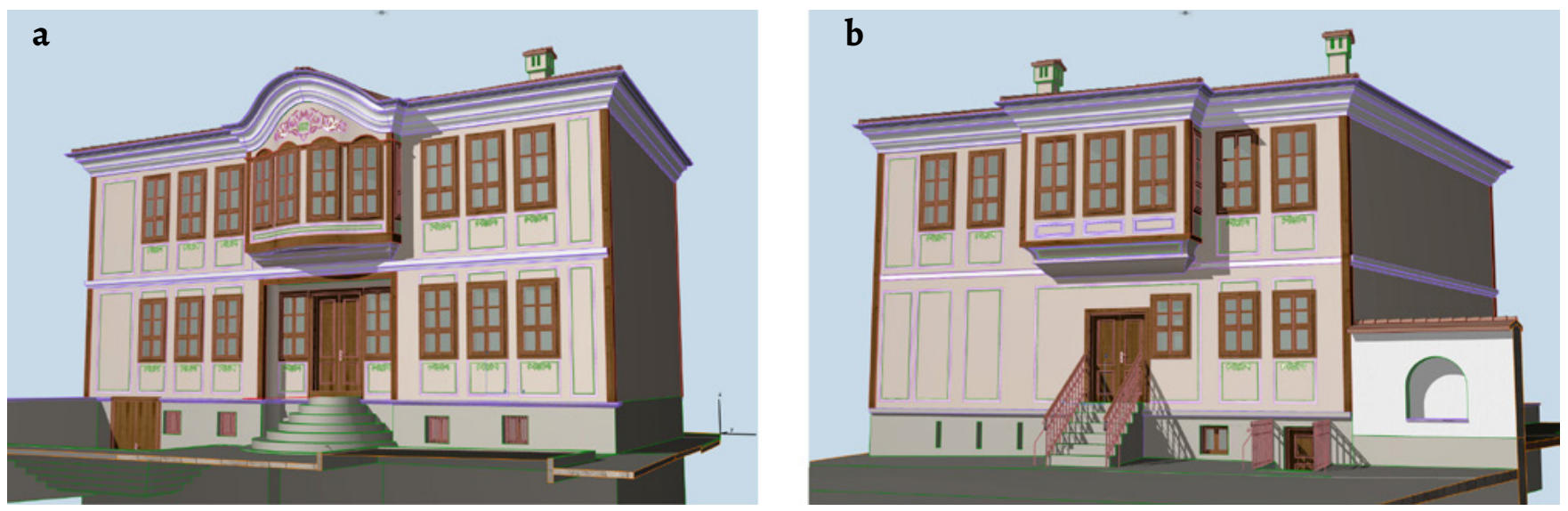

Figure 8. The finished Architectural BIM in ArchiCAD: $a$ ) front; $b$ ) back. 

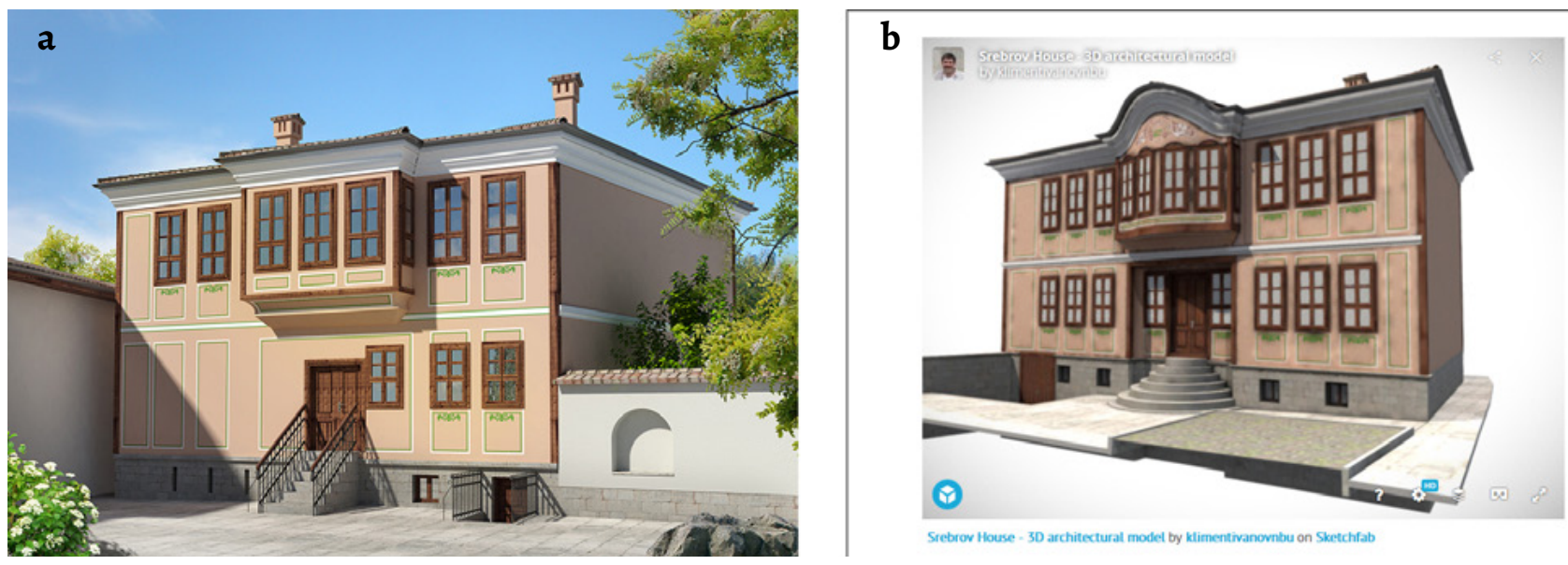

Figure 9. Architectural visualisation (V-Ray) - view to the back (a). Interactive 3D model (Sketchfab) on the NBU website (b).

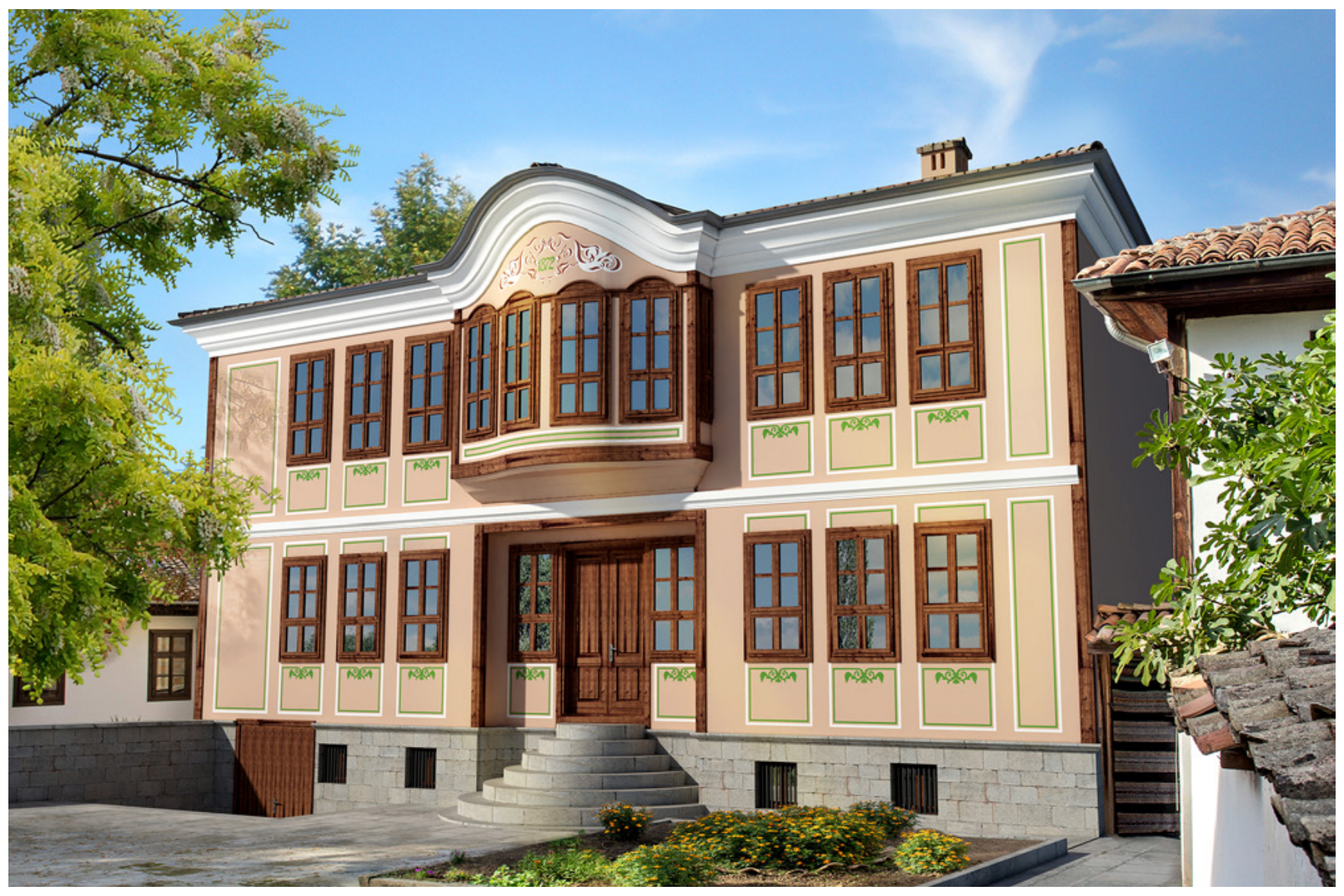

Figure 10. Architectural visualisation (V-Ray) with photomontage - view to the front.

by 3D CAAD applications [6]. So the triangulated surface mesh, also supplied by the surveyors, was abandoned. Using another 3D modelling application was not a feasible option, because it would complicate the workflow and thus make it slower and more expensive. This is the reason the point cloud was chosen as the most suitable option. The problem with the point cloud is that when zoomed in too close, it falls apart and the geometry cannot be read precisely. But the precision is enough for the level of detail needed for the project, which is to model a whole house, not just a small decorative element.

\section{Comparison}

The finished BIM, and also the point cloud, are compared with the published drawings in the book Shumen Revival Houses [7] and with the architectural 2D survey from the municipality (Figure 11b). Two major inconsistencies between the drawings in the book and the BIM can be found. The first is that in the published floor plans in the book, the interior walls are parallel to each other, while in the $2 \mathrm{D}$ survey and in the BIM they are not, and some of the angles of the exterior walls are not correct (Figure 11a). The second is that in the elevation drawings in the book, the 
a

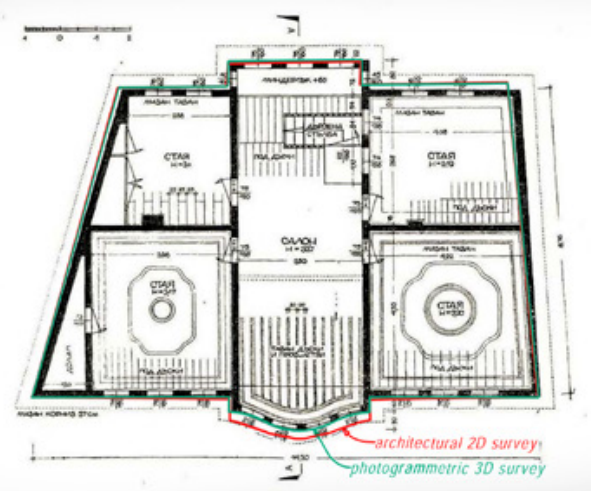

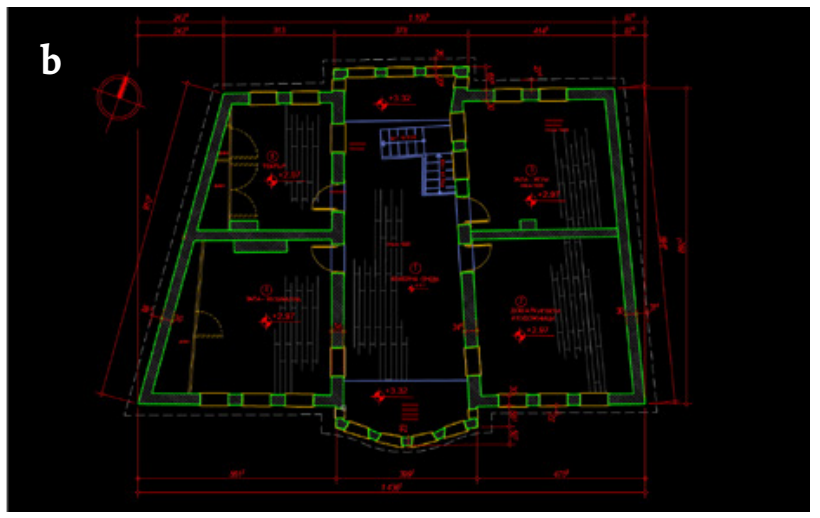

Figure 11. Second storey floor plan drawings: a) handmade drawing from the book Shumen Revival Houses with overlaid contours from the other surveys for comparison: red - architectural 2D survey, green - photogrammetric 3D survey; $b$ ) 2D CAD drawing from the architectural 2D survey in AutoCAD.

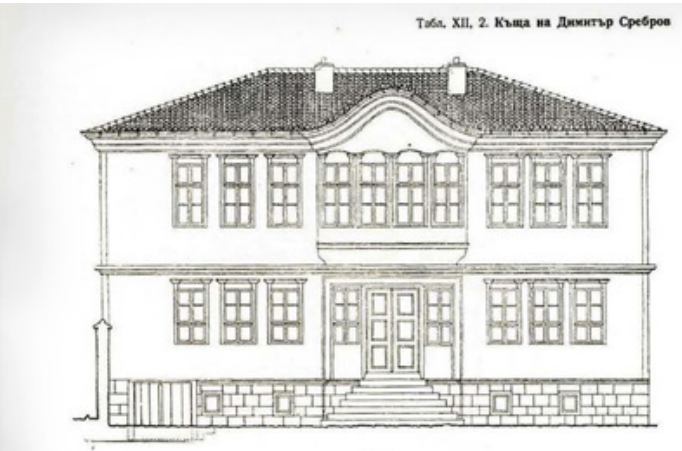

$\mathbf{a}$

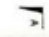

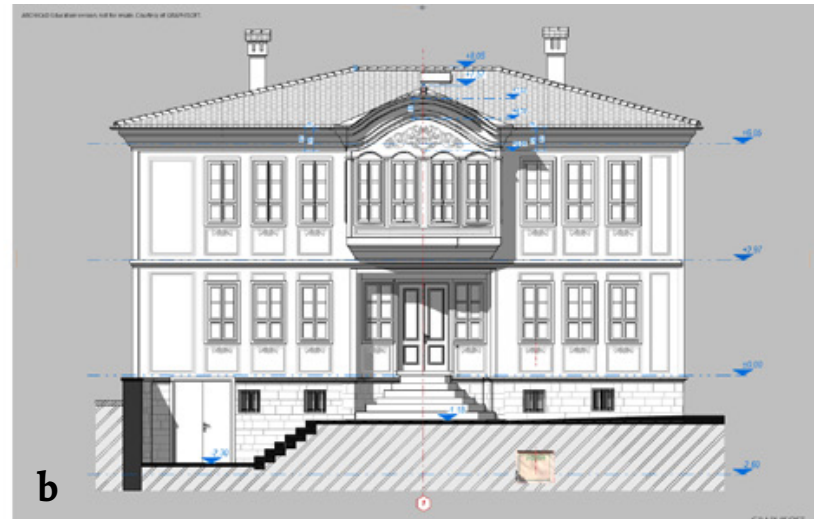

Figure 12. Front elevation drawings: a) handmade drawing from the book Shumen Revival Houses; b) generated drawing form the Architectural BIM in ArchiCAD.

decoration above the windows is completely different from the original and is probably copied mechanically among all the elevations (Figure 12).

The deviations between the 2D survey and the BIM vary for the planar forms and for the curved ones (Figure 13b). For the planar forms they are very small and completely within the acceptable limits. The reason for this is that in the 2D survey, both architectural hand measurements and measurements with geodetic tools have been used, which contributed to the accuracy improvement. These deviations are mostly due to the natural changes in the form of the building with time. For the curved forms, the deviations are significant, even worse than the ones from the published floor plans in the book. These are due to the extremely difficult task of taking measurements by hand from a curved volume, situated high above the ground and difficult to reach.

\section{Level of detail}

The architectural design relies on approximation for proper representation of the architectural idea via architectural
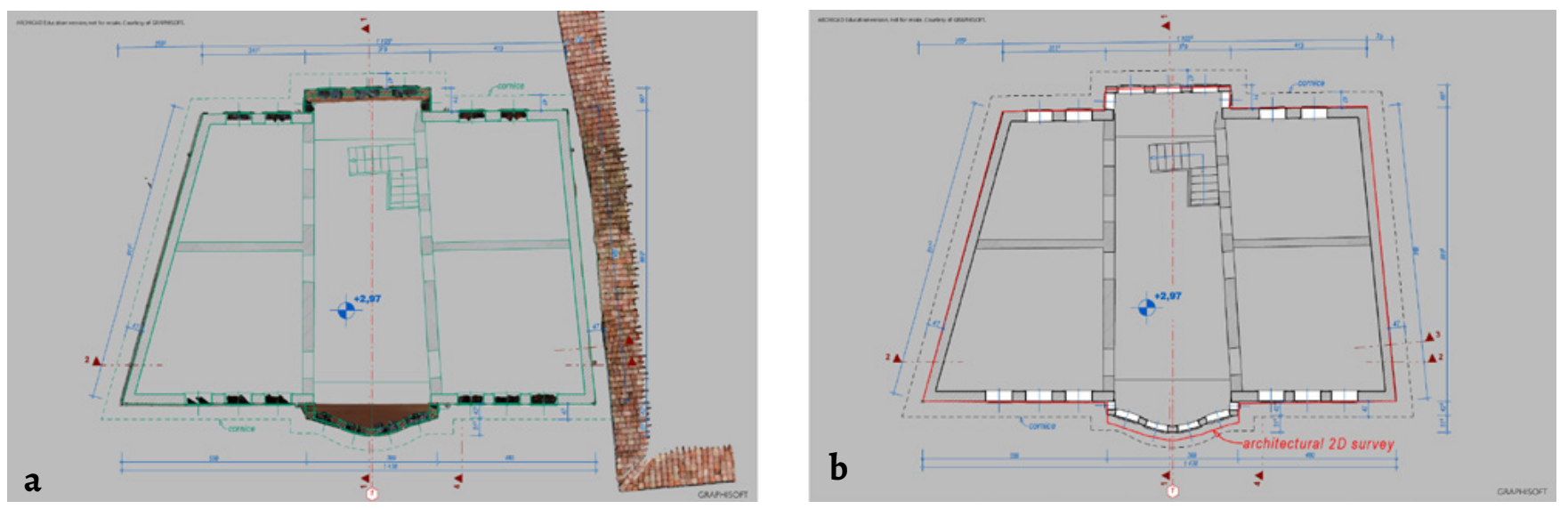

Figure 13. Second storey floor plan drawings - generated from the 3D Architectural BIM in ArchiCAD: $a$ ) with deliberately coloured contours, superimposed over the cut point cloud from the photogrammetric 3D survey; b) standard workflow view with an overlaid contour of the architectural 2D survey. 
drawings or models. The level of detail is defined by the scale, in which the drawings are presented. For example, the main construction drawings are made in scale 1:100 or 1:50, while the detailed drawings are in larger scale like 1:20, 1:10, or even 1:1, and the stucco and rendering are not shown in scale up to 1:50. The stucco can reach a thickness of up to $6 \mathrm{~cm}$, which affects the accuracy of the drawings and, respectively, the model.

Historic buildings pose a different problem - surveying works with the gross dimensions of the walls, respectively the building, which include the combined thicknesses of the wall structure, the stucco, and the cladding. All these components can vary significantly due to the construction techniques of the epoch and the skill of the execution. Besides that, the passing of time affects the building and causes deformation in its form and size. This addresses the issue of the precision of the survey and the accuracy of the model. Paul Richens also raises the question: "when should slight deviations from planarity or symmetry, or irregular spacing [...] be regularised?" [11].

The level of detail of the BIM has to be in conformity with the scale in which the architectural design will be presented, in order to ensure its best apprehension and readability. It doesn't mean that the model is imprecise, but that it has enough detail for execution. The architect defines the necessary level of detail through his knowledge and experience. The "reconstruction inevitably involves choices between different detailed interpretive possibilities, some quite difficult to call" [11]. Printing of the drawings on paper and making physical models is recommended in order to get a proper estimation of the necessary level of detail of the virtual model.

\section{Conclusions}

The traditional method for architectural survey requires the architect to perform interpretations and approximations during the process of making the drawings. The resulting drawings reflect his skills and expertise. Hence, they can be considered as relatively inaccurate. On the other hand, the point clouds, both from photogrammetry or laser scans, are an accurate and objective record of the building "as is". Thus, the point clouds provide a permanent and reliable datum for reference.

The BIM can be regarded as a container of information that represents the process of documentation at a particular moment in time. But it can be complemented and expanded with new data whenever it is required in the future. The availability of the point cloud inside it serves as a permanent reference for additional modelling and design of particular elements. The new data can be about a different level of detail (small-scale decorative elements), new findings (historical layers), or future transformations (reinforcement, adaptive reuse). The BIM, in combination with the photogrammetric point cloud, provides the professionals with an accurate, reliable, and cheap platform for storing and updating the documentation about the cultural heritage (Figure 13a).

The methods for computer-aided design for documentation and preservation of cultural heritage need to be continuously updated. Many of the techniques, published as cutting-edge five or ten years ago, are outdated nowadays [15]. Likewise, many of the tools we used to dream of then have become mainstream practices today. In these terms, this work is providing both the researchers and practitioners with a reliable and proven workflow for $3 \mathrm{D}$ modelling, which will enable them to share the cutting-edge development in the field of architectural design and cultural heritage conservation.

\section{Acknowledgements}

This research is funded by the National Scientific Research Fund and the New Bulgarian University, according to the European Cooperation in Science and Technology (COST) program. The commercial software for the research is used via academic licenses for academic staff members or in the computer laboratories at the New Bulgarian University. All other software is used via free trial versions. The address of the published interactive $3 \mathrm{D}$ model is: https://architecture.nbu.bg/bg/izsledovatelskiproekt-digitalizaciq-na-tradicionna-zhilishtna-arhitektura.

\section{REFERENCES}

1. Georgiev, G., 'Digitalization of Bulgarian cultural heritage', Journal of Economic Development, Environment and People 8(1) (2018) 6-17, https://dx.doi.org/10.26458/jedep.v8i1.606.

2. Murphy, M.; McGovern, E.; Pavia, S., 'Historic building information modelling (HBIM)', Structural Survey 27 (2009) 311-327, https://doi.org/10.1108/02630800910985108.

3. Daskalova-Ivanova, T., 'Rehabilitation of local architectural and structural technologies from the "Central Balkan" region and their application in the architectural education', in Tangible and intangible heritage in civil engineering, Faber, Veliko Tarnovo (2019) 107-115.

4. Apollonio, F. I.; Gaiani, M.; Sun, Z., 'A reality integrated BIM for architectural heritage conservation', in Handbook of Research on Emerging Technologies for Architectural and Archaeological Heritage, ed. A. Ippolito, IGI Global, Hershey PA (2017) 31-65, https://doi.org/10.4018/978-1-5225-0675-1.choo2.

5. Dore, C.; Murphy, M., 'Historic building information modelling (HBIM)', in Handbook of Research on Emerging Digital Tools for Architectural Surveying, Modeling, and Representation, IGI Global, Hershey PA (2015) 233-273, https:// doi.org/10.4018/978-1-4666-8379-2.choo7.

6. Ivanov, K., 'Digital three-dimensional architectural survey of traditional Bulgarian houses - software interoperability and data conversion'/'Цифрово тримерно архитектурно заснемане на традиционни български къщи - взаимодействие и превръщане на данни между софтуеьра', Collection of Scientific Publications, New Bulgarian University, Sofia, 5 (2017-18) 19-29.

7. Angelova, R., Shumenski Vazrozhdenski Кasti/Шуменски възрожденски къщии, Bulgarian Academy of Science, Sofia (1965). 
8. Stefanov, K., '3D documentation of selected examples of Bulgarian traditional residential architecture', ms. (2019).

9. Logothetis, S.; Delinasiou, A.; Stylianidis, E., 'Building information modelling for cultural heritage: a review', in ISPRS Annals of the Photogrammetry, Remote Sensing and Spatial Information Sciences, II-5/W3 (2015) 177-183, https://doi. org/10.5194/isprsannals-II-5-W3-177-2015.

10. Oreni, D.; Karimib, G.; Barazzettia, L., 'Applying BIM to built heritage with complex shapes: The Ice house of Filarete's Ospedale Maggiore in Milan, Italy', in The International Archives of the Photogrammetry, Remote Sensing and Spatial Information Sciences, XLII-2/W5 (2017) 553-560, https://doi. org/10.5194/isprs-archives-XLII-2-W5-553-2017.

11. Richens, P.; Herdt, G., 'Modelling the Ionic capital', in Computation: The New Realm of Architectural Design, ed. G. Cagdas \& B. Colakoglu, eCAADe, Istanbul (2009) 809-816.

12. Tommasi, C.; Achille; C., Fassi, F., 'From point cloud to BIM: A modelling challenge in the cultural heritage field', in The International Archives of the Photogrammetry, Remote Sensing and Spatial Information Sciences, XLI-B5 (2016) 429-436, https://doi. org/10.5194/isprsarchives-XLI-B5-429-2016.

13. Bolognesi, C. M.; Fiorillo, F., 'The integration of 3D survey technologies for an accurate reality-based representation: From data acquisition to BIM modeling', in Conservation, Restoration, and Analysis of Architectural and Archaeological Heritage, IGI Global (2019) 321-345, https://doi.org/10.4018/9781-5225-7555-9.cho13.
14. Palestini, C.; Basso, A.; Graziani, L., 'Integrated photogrammetric survey and BIM modelling for the protection of school heritage, applications on a case study', in The International Archives of the Photogrammetry, Remote Sensing and Spatial Information Sciences, XLII-2 (2018) 821-828, https:// doi.org/10.5194/isprs-archives-XLII-2-821-2018.

15. Brusaporci, S. (ed.), Handbook of Research on Emerging Digital Tools for Architectural Surveying, Modeling, and Representation, IGI Global, Hershey PA (2015).

RECEIVED: 2019.8 .12

REVISED: 2019.12 .27

ACCEPTED: 2020.5.3

ONLINE: 2020.7 .8

\section{(c) (1) (3)}

This work is licensed under the Creative Commons Attribution-NonCommercial-NoDerivatives 4.0 International License. To view a copy of this license, visit http://creativecommons.org/licenses/by-nc-nd/4.o/deed.en. 